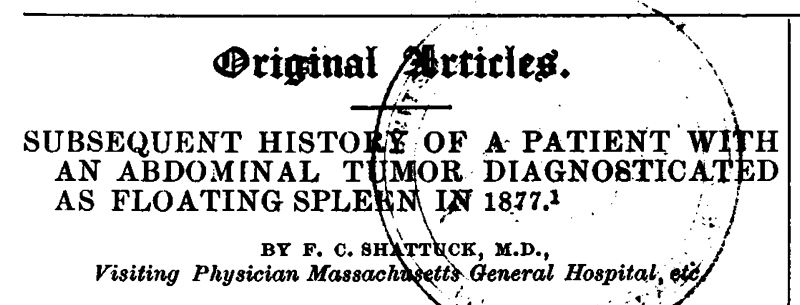

In June, 1878, I had the honor of reading at the annual meeting of the Massachusetts Medical Society, a paper on "Floating Spleen," a paper which was published in the transactions of the Society for that year, and also in the Boston Medical and Surgical Journal. I was led to choose this subject by encountering a case which I believed to be of that nature. Under a lively sense of the fact that it is well for us to report our mistakes and bad cases as well as our triumphs or good cases, I will first very briefly recall the leading facts in the patient's previous history, and then lay before you in more detail his subsequent history, with an account of the autopsy. In July, 1877, I saw for the first time, a well-built young man of eighteen, a baker by trade. A fortnight before he went to bed in usual health, was awakened in the night by severe pain in the left hypochondrium, and then discovered that he had a tumor in his abdomen. After careful and repeated examination I decided that the tumor was an enlarged, displaced, and movable spleen, an opinion concurred in by a professional friend in whose knowledge and skill $I$ had and have the greatest confidence, this gentleman not knowing my opinion until his own was formed and expressed. The possibility that the tumor was a kidney was entertained and rejected. The patient returned immediately to his work, at which I found him busy nearly a year later, when I looked him up and examined him again while preparing my paper.

In July, 1886, never having seen the patient in the interval, I found him in my ward at the Massachusetts General Hospital. He said that four or five years ago he had had an attack of acute pain in the left side with stoppage of water and subsequently hæmaturia. This recurred several times, but there had been no attack for a year and a half. June 17th, he strained himself, as he thought, lifting a barrel of flour, and had been unable to work since, except for a week about a fortnight after his alleged injury. He reported himself as being perfectly well except for dull pain in the lumbar region and left side. The nutrition was very fair. The abdominal tumor showed no marked change since I saw him eight years before, but the axillary, inguinal and cervical glands were somewhat enlarged, and the liver seemed to be uniformly enlarged, the lower edges extending to the umbilicus and across the median line. No nodules could be felt. The urine contained a slight trace of albumen and a few casts; the quantity and specific gravity were normal. 'That there was something more in the case than there had been was evident enough, but I was unable to reach any diagnosis. He declined in strength, but August 10th, it was found necessary to discharge him to make way for cases of typhoid fever which were coming in rapidly, and at the same time our beds were diminished in number by changes in some of the wards.

August 16th, he was admitted into the City Hospi-

1 Read before the Boston Society for Medical Observation, Febru-
ary 7,1887 . tal, the records of which as bearing on his case are most kindly placed at my disposal by Dr. A. L. Mason. He still complained of pain in the back, and of increasing weakness. The legs had become somewhat " numb," and his control over them was imperfect. For the last few days the micturition, previously normal, had been "delayed;" no fever, urine as before. The patella reflexes were increased and ankle clonus was marked; on the outer aspect of the right thigh there was a circumscribed area of diminished sensibility. In the left back, about three inches below the angle of the scapula, was a smooth rounded tumor two inches in diameter, not movable, but adherent to the skin, tense, elastic, fluctuating. (?)

August 21st. Paraplegia was now almost complete and the reflexes were less marked. At times there was retention of urine, the bowels were constipated, there was moderate fever.

August 31st. He passed per urethram about a pint of clear blood. Numerous clots formed in the bladder and were voided with difficulty by the aid of a large catheter. Expressed himself as " perfectly comfortable." The hæmaturia continued several days; there was incontinence of urine and fæces. The hepatic swelling increased, and the edge of the organ was now to be felt two inches below the level of the umbilicus, and in the flank just above the crest of the ilium. 'The other tumor was unchanged.

September 11 th. Several bed-sores had developed over the lower back. He was losing flesh and strength rapidly, though he had a fair appetite and was still "perfectly comfortable."

October 9th. He died, having steadily failed without the appearance of any new symptoms.

Autopsy, twenty-one hours after death, by Dr. Gannett.

Body. Medium size, fairly well developed and nourished. Much emaciated. Rigor mortis present. Anterior abdlominal wall green.

Head. In posterior part left of the parietal bone about two cm. from median line was a circular loss of substance about two $\mathrm{cm}$. in diameter. This was filled with a soft grayish mass, growing in the diploe and projecting both internally and externally about three mm. The brain showed nothing remarkable beyond pallor.

Spinal Column, etc. Spinal canal, opposite last dorsal and first lumbar vertebræ, was about one-half normal size, the lumen being diminished by a growth from the vertebræ into the canal. Spiual cord, corresponding to this point, was softened, more opaque and yellow; all distinction between gray and white matter being lost.

Section through last two dorsal and first two lumbar vertebræ showed that the marrow was almost entirely replaced by a soft, red, and almost gelatinous new growth.

In left vertebral groove, corresponding to these vertebræ, was an ovoid mass, rather larger though not quite so wide as the palm of the hand, and about twice as thick, connecting with the above described vertebral growth.

Ribs. Similar nodules of size of large plums on third and fifth ribs in front on right side, and on fif $t h$ right rib behind, close to vertebral column, all growing from the medulla of the pone.

Heart and lungs were not remarkable.

The spleen was normal in size and weight; it lay 
between the ninth and eleventh ribs, with its anterior border two inches behind the costo-articular line. The gastro-splenic omentum was short; when strong traction was made downward and forward, the spleen could be moved two inches in front of the costo-articular line, and below the eighth cartilage.

The left kidney was represented by a three-lobed mass, about the size of the two closed fists, placed one upon the other. The peritoneum covered not only the anterior surface, but also the posterior surface, like a meso-colon, making the kidney freely movable, so that it could be brought as far as the median line.

On section, the upper portion was found to be made up of a two-lobed, solid mass of a grayish, firm substance, in which yellower and more opaque streaks and specks could be seen. The lower half was a cavity, the size of the fist, with irregular, shreddy walls, having grayish, somewhat translucent and rather friable masses hanging from its inner surface. Outside of this, laterally, was a thin layer of renal substance, in which the distinction between cortex and pyramids could still be made out, though with diffculty, this tissue being quite pale.

The pelvis of the right kidney was deeply injected and thickened; it contained considerable calcareous material. The kidney showed several vertical purulent lines.

The bladder showed thickening on pigmentation of the mucous membrane.

The right ureter had an injected mucous membrane.

The liver measured transversely, twelve; vertically, thirteen ; antero-posteriorly four inches ; weighing a little less than ten pounds. It was thickly studded with gray and red nodules, varying in size from that of a pea to that of a man's fist.

Pathological Diagnosis. Cancer of skull, vertebræ, ribs, kidney, liver. Myelitis from pressure. Cystitis. Pyelo-nephritis.

SUMMARY.

A muscular and well-nourished man of twentyseven has, for at least nine years, had an abdominal tumor, thought to be a movable spleen. He has worked steadily at a laborious trade, and had no symptoms which could possibly be referred to his tumor, except several transitory attacks of hæmaturia. Immediately after lifting a barrel of flour, he is disabled by pain in the back, soon followed by progressive loss of strength, and later, of flesh; enlargement of the liver and superficial lymphatic glands; an elastic tumor below the left scapula; fever, acute myelitis, hæmaturia, and death from exhaustion within less than four months from the time when he was in full activity and apparent health.

The autopsy showed cancer of the skull, vertebræ, ribs, kidney, and liver; myelitis from pressure, cystitis, pyelo-nephritis. The spleen was perfectly normal in size and position.

My original diagnosis was, therefore, entirely wrong. The abdominal tumor was the left kidney, not the spleen. It will be noted that, at the autopsy, Dr. Gannett - to whom I wish to express my great obligation for his careful report of the case - found the peritoneum stretched, and investing the whole kidney, like a meso-colon.

Movable or floating kidney is much more common in women than in men : out of ninety cases collected by Ebstein, eighty-two were females. In congenital malpositions of the kidney, it is usually the left which is anomalous, the organ being fixed, but lying lower down than the normal seat. It is thought that movable conditions of the kidney are acquired, and in more than two-thirds of these it is the right kidney which becomes displaced.

There are two questions suggested by a consideration of the case above reported, to neither of which can a definite answer be given : In the first place, how long was the kidney out of place before I first saw the patient, in 1877? It is, of course, impossible that such elongation of the peritoneum came on suddenly. Tight-lacing was certainly not a factor in causing the dislocation. The occupation of the patient was a laborious one, but I do not know how long he had followed it before the tumor was discovered. As he was only eighteen at the time, it could not have been very long. The second question is: When did this cancerous growth begin? I took no measurement of the tumor when I first saw it, but it is my impression that it was larger than a normal kidney. I considered it to be an enlarged, as well as a floating spleen. It may be that, from twisting of the ureter, the pelvis of the kidney became early somewhat dilated. But to what were the attacks of hæmaturia, recurring between five and one and a half years before his death, due? May they be attributable to acute and temporary strangulation or stoppage of the ureter? When the patient once began to go down hill he went very rapidly; but he considered himself in perfect health up to the time of his supposed strain from lifting the barrel of flour.

\section{REPORT ON THE PROGRESS OF SURGERY.'}

BY H. L. BURRELL, M.D., AND H. W. CUSHING, M.D.

COLOTOMY.

SONNENBURG ${ }^{18}$ has relieved patients suffering from carcinoma of the rectum by operating in the following manner. The abdominal wall was incised in the linea alba, the peritoneal cavity opened, and the colon divided transversely above the point of disease. The lower end was then closed by suture, and dropped back into the abdominal cavity. The superior end was brought forward and fastened into the median incision, below the umbilicus. The advantages claimed for this method are that the surgeon has an opportunity to examine the intestine in regard to the exact nature of the neoplasm, its situation or size, and to change the plan of operation to a more advantageous one, if necessary. The intestine is opened at a known point, and as low as possible, so that solid dejections are voided from the artificial anus. The contraction of the recti muscles serves to constrict the artificial opening, and act as a substitute for a sphincter. The anus, in this position, is more conveniently situated for the patient than in the Amussat or Littré operation. Also, the irritation, pain, ulceration, decomposing discharges, and other complications arising from access of fæces to the intestinal pouch, situated between the seat of stenosis and the artificial opening, is avoided. In case the rectum is wholly occluded, suturing the lower end of the divided intestine into the wound in the linea alba is recommended. This

1 Concluded from page 258 .
18 Berl. Klin. Wochensch., December 6, 1886. 